\title{
Use of Videos in the Information and Communication Technology Open Online Course: insights for learning and development of transformative digital agency with pre- and in-service teachers in Norway
}

Irina Engeness ${ }^{1}$ *, Magnus Nohr ${ }^{1}$, Ammar Bahadur Singh ${ }^{1}$, and Anders Mørch ${ }^{2}$

Corresponding author: Irina Engeness https://orcid.org/0000-0001-5948-4992

\author{
Authors' Affiliation: \\ ${ }^{1}$ Faculty of Education, Østfold University College, Halden, Norway \\ 2 Department of Education, University of Oslo, Oslo, Norway
}

\begin{abstract}
This study examines how videos may support participants' learning in the Information and Communication Technology Massive Open Online Course (ICTMOOC) aimed to develop digital skills with pre- and in-service teachers in Norway and provides an insight into how teachers' interactions with videos may contribute to enhancing their agentic capacity to learn and transformative digital agency. Analyses of participants' interactions with the videos are located in the cultural-historical theory and draw on Galperin's conceptualisation of learning processes.

The data consisted of 501 participants' responses to the questionnaire administered to all pre- and inservice teachers engaged in the ICTMOOC in 2014-2018. Mixed methods were applied to analyse the data by providing quantitative and qualitative evidence about the processes of videos' use.

Findings reveal the patterns of participants' interactions with videos: i) seeking explicit information about how to engage in learning; ii) seeking assistance while engaged with the assigned tasks, iii) support to compare learning outcomes with the requirements outlined in the videos. In doing so, the videos provided orienting, executive and controlling support and might have contributed to enhancing participants' capacity to learn in digital environments and their transformative digital agency. Majority of participants used videos for executive support and the learners preferred videos in the range of 5-10 min. By providing these types of support by the videos, a learning activity carries a new function as $a$ tool for studying the essence of learning in digital environments.

These findings have implications for the design of videos in online courses. They also emphasise the crucial importance of awareness about the type of support videos provide to enhance participants' learning in digital environments.
\end{abstract}

Keywords: Videos, online learning, MOOCs, agency in learning to learn, transformative digital agency, Galperin

\subsection{Introduction}

This study examines the participants' experiences of their use of videos in the Information and Communication Technology Massive Open Online Course (ICTMOOC) aimed to develop digital skills with pre- and in-service teachers in Norway. The study also provides an insight into how teachers' interactions with videos may contribute to enhancing their agentic capacity to learn, and transformative digital agency. Massive Open Online Courses (MOOCs) have become a buzzword in education and over the next ten years, e-learning is projected to grow 
fifteen-fold, accounting for $30 \%$ for all educational provision (Lillejord, et al., 2018). However, such a new form of educational delivery influences and challenges learning and teaching practices. On the one hand, MOOCs may also offer the possibility for innovative instructional designs to support self-regulated learning and enhance participants' agentic capacity to learn (Bartolomé-Pina \& Steffens, 2015). On the other hand, MOOCs are characterised by high dropout and low completion rates (Kennedy, 2014; Singh \& Mørch, 2018). It has been argued that effective MOOC design is a key factor in combating these challenges (Conole, 2015) and videos have become a central element in the design of MOOCs and online courses (Bonafini, et al., 2017; Evans, et al., 2016; Guo et al., 2014; Hew, 2016; Reutemann, et al., 2016; Rose, 2009). To engage in learning in MOOCs, participants should develop their understanding of how to go about learning in digital environments and enhance their agentic capacity to learn. Therefore, videos (together with other resources) might contribute to enhancing such a capacity with participants as they move forward as self-regulated learners in online environments to become increasingly competent users of their knowledge.

While unpacking Vygotskian notion of social situation of development, Edwards (2015), conceptualises learners' agency as an ability to propel themselves forward recognising and responding to the demands in tasks and with increasing competence, repositioning themselves within a knowledge domain. This resonates with Mäkitalo's (2016) understanding of learners' agency as "the capacity of humans to distance themselves from their immediate surroundings and ... to intervene in and transform the meaning of, situated activities" (p.64, emphasis in original). In our context, this implies an ability of learners to engage in interactions with video resources in MOOCs to be able to utilise the support provided by the videos to resolve the problem situations and propel themselves forward in their learning. In learning aimed at enhancing participants' digital competence, Brevik and colleagues (2019) introduced the notion of transformative digital agency as competence to take initiatives and transform practices by selecting relevant digital tools. Transformative digital agency arises as a necessity when learners are placed in demanding situations involving challenges or conflict of motives, thus creating a wish or need to break out of the current situation. In many ways learning in MOOCs can be seen as a demanding situation involving challenges for the participants to understand how to engage in learning and how to utilise available digital (video) resources to support their learning. Research on how videos may enhance participants' agentic capacity to learn in online environments is still relatively scarce. This study addresses this gap by examining the pre- and in-service teachers' experiences about the types of support the video resources provided and the preferred length of videos. In additions, we attempt to outline the implications of the support 
provided by the videos for enhancing participants' agentic capacity to learn and transformative digital agency.

\subsection{Agency in learning to learn and transformative digital agency}

Research defines learning to learn as metacognition: knowledge and awareness about one's cognition in general (Pintrich, 2002; Schraw, et al., 2006), which, together with motivational beliefs and cognitive strategies, constitute self-regulated learning (Winne, 1997; Winne \& Perry, 2000). It has been shown that good self-regulators do much better academically than poor self-regulators (Zimmerman \& Pons, 1986) and students' belief in their capacity to manage their learning provides the power and enhances performance accomplishments (Bandura, 2001; Bandura, et al., 1996; Zimmerman \& Bandura, 1994).

To enhance students' agentic capacity to self-regulated learning, Zimmerman's (2002) earlier work has taken a broad perspective, outlining strategies such as goal setting, strategy use, and self-evaluation. In doing so, he has emphasised that mastery of these strategies is social in nature and can be learned from instruction and modelling by parents, teachers, and coaches. Latterly he has pointed to how learners' focus on how they activate, alter, and, sustain specific learning strategies in social as well as solitary contexts is especially relevant for their development as learners (Zimmerman, 2008).

In line with Zimmerman's attention to the social origins of students' self-regulation, guidance has also been offered to teachers, to encourage them to develop self-regulated learners. Pintrich (2002), for example, argues that explicitly teaching metacognitive knowledge across different subject areas and contexts to facilitate its development with learners is needed and conceptualises self-regulated learning as "an active constructive process whereby learners set goals for their learning, monitor, regulate, and control their cognition, motivation, and behaviour, guided and constrained by their goals and the contextual features of the environment" (Pintrich \& Zusho, 2002, p.64).

However, the evolvement of new educational environments (MOOCs) urges the need to understand how available (video) resources might enhance participants' agentic capacity to self-regulated learning in MOOCs and their development as learners. In MOOCs, individuals must determine when, how and with what content and activities they engage (Milligan \& Littlejohn, 2014). Studies examining learning in online environments have identified positive correlations between self-regulated learning behaviour and academic achievement (Azevedo \& Cromley, 2004; Barnark-Brak et al., 2010; Serdyukov \& Hill, 2013; Wang et al., 2013). By interacting with digital resources learners may develop their digital agency which is 
transformative in nature (Brevik et al., 2019; Lund et al., 2019). The transformative nature of digital agency implies learners' ability to transfer their interactions with digital resources into an opportunity for learning and development and therefore transformative digital agency is inherently connected with the learners' agentic capacity to learn. Videos (and other resources) might contribute to developing participants' understanding about how to engage in learning in MOOCs and, therefore, there is a need to examine the types of support video resources provide to learners.

\subsection{Video resources in online courses and MOOCs}

Videos in MOOCs used both synchronously and asynchronously, can vary in the position within the course, and in purpose, such as: (a) introductory videos in which course instructors explain the course and its purpose, (b) animations with audio narration in which the course content is explained, (c) video lectures given to real students, and (d) videos with built-in questions (Bonafini, et al., 2017). In studies on the use of lecture videos, students report enjoying the videos and find their classes engaging (Choi \& Johnson, 2005; Whatley \& Ahmad, 2007). Through videos, information can be presented in an attractive and consistent manner (Yousef, et al., 2014; Zhang, et al., 2006) and visualise phenomena that are difficult to convey with texts or static pictures (Colasante, 2011). Guo and colleagues (2014) carried out, as the authors claim, the largest-scale study on students' video engagement in MOOCs, using data from 6.9 million video watching sessions across four courses on the edX MOOC platform. Their findings show that shorter and informal talking-head videos and videos produced with a more personal feel could be engaging for learners. They found higher dropout rates in longer videos, re-watching sessions, and tutorials rather than lectures. Like Guo and colleagues (2014), other researchers (Reutemann, et al., 2016) found that talking head videos are the most preferred by learners in four MOOC platforms (edX, Coursera, FutureLearn, and Iversity). However, depending on the video style, students appear to interact differently with the course video materials. Kim and colleagues (2014) identified five student interaction patterns with videos: starting from the beginning of new material, returning to missed content, following a tutorial step, replaying a brief segment, and repeating a non-visual explanation. Videos can also provide a valuable context for learning and generate a common experience for students to discuss and reflect on concepts and ideas as in anchored instruction (Bonk, 2011; Langset, et al., 2018; Singh \& Mørch, 2018; Sherer \& Shea, 2011). By generating a common experience for learners, videos can enhance students' engagement in collaborative activities and promote different learning styles (Calandra, et al., 2006; Goulah, 2007; Greenberg \& Zanetis, 2012; Pea 
\& Lindgren, 2008; Zhang et al., 2006). For instance, time-anchored commenting interfaces allow learners to watch and exchange comments simultaneously, thus transform engagement with videos from passive to active (Lee et al., 2015). In addition to different purposes, videos may also vary in length.

The length of the educational videos in MOOCs is a widely discussed topic. Some researchers argue that short videos are most suitable for educational purposes (Bonk, 2011; Guo et al., 2014). On the one hand, Guo and colleagues (2014) introduced a "six minutes rule" as an optimum length for videos in MOOCs. On the other hand, Lagerstrom and colleagues (2015) believe that the "six-minute rule," valid for a MOOC environment, does not capture the video viewing behaviours of students in standard college courses and how long students watch a video depends on how motivated the student is to study. Based on the data from single watching sessions, a rule of thumb for maximum video length in the range of 12-20 minutes is introduced (Lagerstrom, et al., 2015).

Although the observations outlined here indicate that videos can be a powerful resource to enhance students' engagement in learning, studies tend to lack detail on how participants interact with videos in online courses and how videos may contribute to the development of learners' agentic capacity to learn and their transformative digital agency. The discussion on the preferred length of videos is also lacking consensus. We examined participants' interaction patterns with videos by zooming in with the lens of a cultural-historical theory (Engeness \& Lund, 2018).

\subsection{Theoretical perspective}

A cultural-historical perspective has been chosen to examine participants' interaction patterns with videos in the ICTMOOC (Clarà \& Barberà, 2013, Engeness, 2019). Vygotsky was the first to suggest that the source of learning and development of the human mind lies on the external (social) plane (Vygotsky, 1980). Tools (material and linguistic) that mediate these activities are initially directed outwards, connecting the learner with the surrounding world and, by acquiring a particular meaning, transform into signs directed inwards, to the mental plane of the learner (Arievitch \& Stetsenko, 2014). In our case, videos embedded in the ICTMOOC act as material mediational tools that connect learners with the public meanings that are valued in cultures. These cultures include contemporary digital software and its pedagogic potential. Vygotsky put particular emphasis on the quality of the mediational tools learners interact with and the effect these tools have on students' learning and development (Arievitch \& Stetsenko, 
2000). The quality of video resources and understanding the types of support videos provide to learners would seem to be crucial.

However, Vygotsky did not explain how specific qualities of tools affect students' learning (Clarà, 2017). A cultural-historical scholar Galperin extended Vygotsky's argument about the effect the qualities of tools may have on students' learning by introducing three types of orientation. Galperin understood orientation as a way of structuring of the learning process and utilising appropriate mediational tools and their pedagogic potential. He argued that orientation can be specific to solve a particular task, or it can be used in several learning situations. In addition, the orientation can be either supplied to the learners in its final form ready to be used in a learning activity or it can be constructed by learners. The construction of orientation by learners can happen either by the method of trial and error or by using an approach offered by the teacher.

Based on these premises, Galperin identified three types of orientation: i) incomplete, where mediational tools and the essential characteristics of the target concept are identified by learners through trial and error. In this case, learning happens slowly with many mistakes and is extremely sensitive to the slightest changes in the conditions of the learning activity; ii) complete, where learners are informed about all mediational tools that encapsulate the essential characteristics of the target concept. However, these mediational tools are specific and can be used only in one case, for example, when solving a particular problem. Learning happens quickly and with minimum mistakes; however, the transfer of skills and knowledge developed during such an activity is possible only when there is a close similarity in the problems and learning situations and iii) complete and constructed by learners following an offered approach aimed at identifying the essential characteristics of the target concept. By using an offered approach, a specific orientation can be constructed by learners suited to solve a problem. With the third type of orientation (complete and constructed by learners following an offered approached), learning happens quickly, with minimum mistakes and the skills and knowledge developed during the learning activity can be transferred to other learning situations. The students develop their understanding of how to go about learning and their agency in learning to learn may be enhanced (Engeness, 2019). These three types of orientation will be used as a lens to examine the types of support videos provided to the learners in the ICTMOOC. Such use of Galperin's theory is innovative and we are interested to explore whether the lens of the types of orientation will help in our analysis of the pedagogic potential of videos in digital environments. The following research questions are addressed: 
RQ1: What did the pre- and in-service teachers say about the types of support the video resources in the ICTMOOC provided and what length of videos was preferred by the learners?

RQ2: What are the implications of the support provided by the videos for enhancing participants' agentic capacity to learn and transformative digital agency?

\subsection{Method}

\subsection{Participants and setting}

Data collection was conducted through the questionnaire administered to all pre- and inservice teachers engaged in the ICTMOOC in 2014 - 2018. The pre-service teachers took the ICTMOOC as a part of their teacher training programme and the requirement to enrol in the course was a General Certificate of Secondary Education ${ }^{1}$. The in-service teachers engaged in the course to enhance their professional development and these were the teachers from all levels in the education system: kindergarten, primary and secondary school teachers and the teachers that work in the Universities and Colleges. The language of tuition in the ICTMOOC is Norwegian and the majority of the participants were from Norway and some were from Sweden.

The questionnaire was administered online on the completion of the course and it aimed to examine participants' experiences in the ICTMOOC. The questionnaire included: i) general information about pre- and in-service teachers, ii) participants' learning experiences in the ICTMOOC and iii) teachers' facilitating of the learning process in the ICTMOOC. The questionnaire included twenty-two questions; some questions applied a Likert scale from one to five and some questions required detailed qualitative answers. Table 1 shows the number of respondents to the questionnaire in $2014-2018$, their background and their general evaluation of the ICTMOOC.

Table 1. The number of respondents to the questionnaire in 2014-2018, their background and their general evaluation of the ICTMOOC

\begin{tabular}{cccll}
\hline Years & $\begin{array}{c}\text { Number of } \\
\text { respondents }\end{array}$ & $\begin{array}{c}\text { Male/ } \\
\text { Female } \\
\text { Mean, } \\
\end{array}$ & $\begin{array}{c}\text { Professional background } \\
\text { Mean, (M) }\end{array}$ & $\begin{array}{c}\text { General evaluation of the ICTMOOC } \\
\text { Mean, (M) (SD) }\end{array}$ \\
\hline $2014-$ & 501 & Male & In-service teacher M=73.4\% & Very weakly satisfied M=1.34\% (0.97) \\
2018 & & M=22.8\% & Pre-service teacher M=20.6\% & Weakly satisfied M=0.9\% (2.01) \\
& & Other M=8.8\% & Somewhat satisfied M=2.94\% (2.27) \\
& & & Strongly satisfied M=28.82\% (4.71) \\
& Female & & Very strongly satisfied M=67.67\% (6.42) \\
\hline
\end{tabular}

\footnotetext{
${ }^{1}$ In Norwegian: Vitnemål
} 


\subsection{ICTMOOC}

The ICTMOOC was first introduced in Norway in 2014. The course was developed by the researchers and development specialists from Østfold University College. The ICTMOOC has a structure of an $\mathrm{xMOOC}$, it is built in the Canvas platform and is aimed to enhance the development of digital skills with pre- and in-service teachers. Researchers define xMOOCs as institutionally focused, reliant on video lectures and automated assessment through quizzes courses (Bayne \& Ross, 2014; Singh \& Mørch, 2018) and all these elements are present in the ICTMOOC. The ICTMOOC consists of 10 Modules to be completed by the participants progressively over 10 weeks.

Each Module contains textual information, videos, individual tasks, and multiple-choice quizzes. In total, there are 223 videos in the course, 174 of them are produced by the course developers and stored at the YouTube Channel. 179 videos are tutorials/instructional videos and forty-one videos discuss the pedagogical aspects of the use of digital tools. The total length of all videos in the course is $22 \mathrm{~h} 29 \mathrm{~min} 39 \mathrm{sec}$ and the average length of a video is $6 \mathrm{~min} 3 \mathrm{sec}$. The list of Modules included in the ICTMOOC, the progress plan the participants are to follow, the overview of the videos and the length of the videos in the ICTMOOC are presented in Table 2.

Table 2. Progress plan and the videos in the ICTMOOC

\begin{tabular}{|c|c|c|c|c|c|c|c|}
\hline Module & $\begin{array}{l}\text { Progress } \\
\text { plan } \\
\text { Week }\end{array}$ & $\begin{array}{l}\text { Number } \\
\text { of videos }\end{array}$ & $\begin{array}{l}\text { Length of } \\
\text { videos } \\
\text { h:min:sec }\end{array}$ & $\begin{array}{l}\text { Produced } \\
\text { internally }\end{array}$ & $\begin{array}{l}\text { Produced } \\
\text { externally }\end{array}$ & $\begin{array}{l}\text { Pedagogical } \\
\text { videos }\end{array}$ & $\begin{array}{c}\text { Tutorial } \\
\text { videos }\end{array}$ \\
\hline Module 0. Introduction & 34 & 3 & $1: 10: 11$ & 3 & 0 & 2 & 1 \\
\hline $\begin{array}{l}\text { Module 1. Taking notes } \\
\text { digitally }\end{array}$ & 35 & 30 & 1:59:15 & 26 & 4 & 2 & 28 \\
\hline $\begin{array}{l}\text { Module 2. Microsoft Office } \\
\text { and collaborative writing }\end{array}$ & 36 & 29 & $2: 34: 53$ & 28 & 1 & 1 & 28 \\
\hline Module 3. Digital & 37 & 22 & $2: 33: 19$ & 22 & 0 & 4 & 18 \\
\hline Presentations & & & & & & & \\
\hline Module 4. Photo Editing & 38 & 14 & 1:45:50 & 13 & 1 & 1 & 13 \\
\hline $\begin{array}{l}\text { Module 5. Video and } \\
\text { Animations }\end{array}$ & 39 & 23 & 2:08:51 & 17 & 6 & 3 & 20 \\
\hline $\begin{array}{l}\text { Module 6. Digital } \\
\text { Assessment }\end{array}$ & 40 & 22 & $2: 27: 15$ & 20 & 2 & 4 & 18 \\
\hline Module 7. Interactive & 41 & 34 & $3: 08: 21$ & 10 & 24 & 4 & 27 \\
\hline
\end{tabular}




\begin{tabular}{|c|c|c|c|c|c|c|c|}
\hline Module 8. Web Publishing & 42 & 9 & $0: 47: 52$ & 8 & 1 & 2 & 7 \\
\hline Module 9. Student & 43 & 11 & 1:11:36 & 9 & 2 & 7 & 4 \\
\hline \multicolumn{8}{|l|}{ Response Systems } \\
\hline Module 10. Digital Tools & 44 & 26 & 2:42:16 & 18 & 8 & 11 & 15 \\
\hline \multicolumn{8}{|l|}{ for Students with Individual } \\
\hline \multicolumn{8}{|l|}{ Needs and Copyright } \\
\hline Total & 10 & 223 & 22:29:39 & 174 & 49 & 41 & 179 \\
\hline Average length of videos & & & 0:06:03 & & & & \\
\hline
\end{tabular}

In several Modules, students are expected to complete practical exercises to develop digital skills with the participants, give and receive peer feedback and submit examination assignments. A typical example of assignments included in the ICTMOOC is the task included in Module 3 Digital Presentations: Creating a PowerPoint (Figure 1).

\section{Creating a PowerPoint}

Step 1: Create a PowerPoint about yourself (8 slides).

Step 2: Choose a background theme for all slides apart from slide number 2 where you insert a picture of your home place as a background.

Step 3: Save your PowerPoint: Your_name.pptx

Step 4: Submit your PowerPoint in Canvas.

Figure 1. Assignment Creating a PowerPoint

On successful completion of the ICTMOOC (evaluated to passed or failed), participants are awarded 15 ECTS Credits (European Credit Transfer and Accumulation System). Over 80\% of students passed the ICTMOOC in 2014-2018.

\subsection{Data and analysis}

To address the research questions in this study, the following questions were included in the questionnaire administered to the participants in the ICTMOOC in 2014-2018: 11) What is your overall experience about the use of videos in the ICTMOOC? (applied a Likert scale from one to five (one = 'very weakly satisfied,' two = 'satisfied,' three = 'somewhat satisfied,' four = 'strongly satisfied' and five = 'very strongly satisfied'), 12) What do you think about the length of videos in the ICTMOOC? (applied a Likert scale from one to five (one = 'too short,' two $=$ 'short,' three = 'appropriate,' four = 'long' and five = 'too long'); 13) What length of videos do you think is appropriate in the ICTMOOC? (participants were to mark one of the 
suggested lengths: 0-2 min, 3-4 min, 5-6 min, 7-10 min, 11-15 min, 16-20 min, 21-30 min, and 31-45 min) and 14) How did you use videos in your learning in the ICTMOOC? (participants were to provide detailed descriptive answers).

The data consisted of 501 participants' responses to questions 11, 12, 13 and 14. All responses provided by the participants were anonymous and voluntary. Mixed methods (Creswell, 2012) were applied to analyse the data by providing quantitative and qualitative evidence about the processes of videos' use.

To examine the preferred length of videos in the ICTMOCC, the participants' responses to questions 11, 12 and 13 were analysed.

To examine participants' interaction patterns with the videos in the ICTMOOC, students' responses to question 14 were analysed qualitatively by following the steps of thematic analysis: i) transcription of data, ii) coding of data and iii) analysis of data (Castleberry \& Nolen, 2018; Clarke \& Braun, 2014). We imported the participants' responses to NVivo 12 and conducted an initial open coding (Miles \& Huberman, 1994) using an inductive approach in a thematic analysis (Clarke \& Braun, 2014; Van Manen, 2016) without any predetermined categories (Patton, 2015). To uncover thematic aspects, the following approaches to coding may be applied: i) a holistic approach that targets the underlying meaning of the entire text, ii) a selective approach in which one examines which phrases or statements are considered to illuminate the phenomenon being examined and iii) a detailed approach in which all sentences are individually examined with regard to their significance to the phenomenon (Philipsen, et al., 2019; Van Manen, 2016). In this study, a detailed approach was applied.

The codes identified by the detailed approach were presented either in the form of a descriptive label that directly described or was taken from the participants' responses. Thereafter, the codes were put into context with each other to create themes. Clarke and Braun (2014) define themes as patterns in the codes; they take the numerous pieces of related code to show a bigger picture of what is being portrayed. Therefore, the single codes from the open coding process were grouped into larger themes to represent patterns of participants' interactions with the videos in the ICTMOOC. These themes are presented in 3.0 Findings section of this article. Once the themes were identified, they were examined through the analytic lens offered by Galperin's types of orientation to begin to unpack how the available video resources supported participants in the learning process. To ensure reliability of the results, thematic analysis of participants' responses was conducted by the research team.

\subsection{Findings}




\subsection{Analysis of participants' preferences about the length of the videos in the ICTMOOC}

The analysis of participants' preferred length of videos in the ICTMOOC starts by examining students' responses about their overall experience of using videos in the ICTMOOC (Q 11: What is your overall experience about the use of videos in the ICTMOOC) (Table 3).

Table 3. Participants' responses about their overall experience of using videos in the ICTMOOC

\begin{tabular}{lcccccc}
\hline \multicolumn{1}{c}{ Years } & $\mathbf{2 0 1 4}$ & $\mathbf{2 0 1 5}$ & $\mathbf{2 0 1 6}$ & $\mathbf{2 0 1 7}$ & $\mathbf{2 0 1 8}$ & Mean (M) \\
\hline Very weakly satisfied & $1.3 \%$ & $0 \%$ & $0.5 \%$ & $0.5 \%$ & $0.7 \%$ & $\mathrm{M}=0.60 \% \mathrm{SD}=0.47$ \\
Weakly satisfied & $0 \%$ & $4.5 \%$ & $0 \%$ & $0 \%$ & $0 \%$ & $\mathrm{M}=0.90 \% \mathrm{SD}=2.01$ \\
Somewhat satisfied & $6 \%$ & $3.1 \%$ & $2.2 \%$ & $0.8 \%$ & $0.3 \%$ & $\mathrm{M}=2.48 \% \mathrm{SD}=2.26$ \\
Strongly satisfied & $34.9 \%$ & $24.2 \%$ & $30.6 \%$ & $28.5 \%$ & $23.6 \%$ & $\mathrm{M}=28.36 \% \mathrm{SD}=4.68$ \\
Very strongly satisfied & $57.8 \%$ & $68.2 \%$ & $66.7 \%$ & $70.2 \%$ & $75.4 \%$ & $\mathrm{M}=67.66 \% \mathrm{SD}=6.42$
\end{tabular}

The data show that the majority of pre- and in-service teachers were very strongly satisfied $(M=67.66 \%, S D=6.42)$ with the support the videos provided in the ICTMOOC.

Table 4 presents participants' responses about their experiences of the length of videos in the ICTMOOC (Q 12: What do you think about the length of videos in the ICTMOOC?)

Table 4. Participants' responses about the length of videos in the ICTMOOC

\begin{tabular}{lcccccc}
\hline \multicolumn{1}{c}{ Years } & $\mathbf{2 0 1 4}$ & $\mathbf{2 0 1 5}$ & $\mathbf{2 0 1 6}$ & $\mathbf{2 0 1 7}$ & $\mathbf{2 0 1 8}$ & Mean (M) \\
\hline Way too short & $0 \%$ & $0 \%$ & $0 \%$ & $0 \%$ & $0 \%$ & $\mathrm{M}=0.00 \% \mathrm{SD}=0.00$ \\
Too short & $1.2 \%$ & $0 \%$ & $0 \%$ & $0 \%$ & $0.7 \%$ & $\mathrm{M}=0.38 \% \mathrm{SD}=0.55$ \\
Appropriate & $62.7 \%$ & $80 \%$ & $83.6 \%$ & $93.1 \%$ & $92.9 \%$ & $\mathrm{M}=82.46 \% \mathrm{SD}=12.45$ \\
Too long & $39.8 \%$ & $23.1 \%$ & $16.4 \%$ & $8.5 \%$ & $9.2 \%$ & $\mathrm{M}=19.40 \% \mathrm{SD}=12.86$ \\
Way too long & $0 \%$ & $0 \%$ & $1.4 \%$ & $0.8 \%$ & $0 \%$ & $\mathrm{M}=0.44 \% \mathrm{SD}=0.64$ \\
\hline
\end{tabular}

The data reflect that the majority of participants $(\mathrm{M}=82.46 \%, \mathrm{SD}=12.45)$ considered the length of videos (average 06min 03sec) appropriate.

Table 5 presents participants' responses about the preferred length of videos in the ICTMOOC. (Q13: What length of videos do you think is appropriate in the ICTMOOC?)

Table 5. Participants' responses about the preferred length of videos in the ICTMOOC

\begin{tabular}{ccccccc}
\hline Years & $\mathbf{2 0 1 4}$ & $\mathbf{2 0 1 5}$ & $\mathbf{2 0 1 6}$ & $\mathbf{2 0 1 7}$ & $\mathbf{2 0 1 8}$ & Mean (M), \\
\hline $0-2 \mathrm{~min}$ & $1.1 \%$ & $1.7 \%$ & $1.2 \%$ & $1.4 \%$ & $2,1 \%$ & $\mathrm{M}=1.50 \% \mathrm{SD}=0.41$ \\
$3-4 \mathrm{~min}$ & $4.7 \%$ & $9.2 \%$ & $4.3 \%$ & $5.1 \%$ & $8,3 \%$ & $\mathrm{M}=6.32 \% \mathrm{SD}=2.26$ \\
$5-6 \mathrm{~min}$ & $40.7 \%$ & $27.3 \%$ & $42.1 \%$ & $36.2 \%$ & $40.4 \%$ & $\mathrm{M}=37.34 \% \mathrm{SD}=6.03$ \\
$7-10 \mathrm{~min}$ & $40.4 \%$ & $45.5 \%$ & $41.5 \%$ & $38.9 \%$ & $37.4 \%$ & $\mathrm{M}=40.74 \% \mathrm{SD}=3.08$ \\
$11-15 \mathrm{~min}$ & $9.3 \%$ & $12.2 \%$ & $8.7 \%$ & $13.5 \%$ & $7.8 \%$ & $\mathrm{M}=10.30 \% \mathrm{SD}=2.43$ \\
$16-20 \mathrm{~min}$ & $3.5 \%$ & $4.1 \%$ & $2,2 \%$ & $4.1 \%$ & $3.3 \%$ & $\mathrm{M}=3.44 \% \mathrm{SD}=0.78$ \\
$21-30 \mathrm{~min}$ & $0.3 \%$ & $0 \%$ & $0 \%$ & $0 \%$ & $0.3 \%$ & $\mathrm{M}=0.12 \% \mathrm{SD}=0.16$ \\
$31-45 \mathrm{~min}$ & $0 \%$ & $0 \%$ & $0 \%$ & $0.8 \%$ & $0.4 \%$ & $\mathrm{M}=0.24 \mathrm{SD}=0.36$ \\
\hline
\end{tabular}


The data demonstrate that the students preferred the videos in the range of 5-6 min $(\mathrm{M}=37.34 \%, \mathrm{SD}=6.03)$ and the videos in the range of 7-10 $\mathrm{min}(\mathrm{M}=40.74 \%, \mathrm{SD}=3.08)$. These findings indicate the need to examine the patterns of the students' interactions with the videos in the ICTMOOC qualitatively.

\subsection{Analysis of participants' interactions with videos in the ICTMOOC}

The qualitative thematic analysis (Castleberry \& Nolen, 2018; Clarke \& Braun, 2014) identified four main themes that reflect the interaction patterns of the participants with the videos and the types of support the videos provided to the learners in the ICTMOOC. These themes are: orienting, executive, controlling and other support. Estimated in NVivo 12, the percentage coverage of the types of support the videos in the ICTMOOC provided to the students is: orienting support $18.12 \%$; executive support $52.11 \%$, controlling support $14.76 \%$ and other support $15.01 \%$.

The data highlight the differences in the percentage coverage of the type of support the videos in the ICTMOOC provided to the students: the videos provided more executive support than orienting, controlling or other support. In what follows, we examine the nature of these types of support in detail.

\subsubsection{Orienting support}

The students reported they watched the videos before engaging in the assigned task (Figure 2):

\footnotetext{
In every task, I always watched the videos first before engaging in the task.
I used the information from the videos to understand what tasks I had to complete.
I watched all videos to develop an understanding of how to solve the task and become aware of the useful
functions in the software.

Figure 2. Participants' responses about the orienting support of the video resources

The participants indicated that they were seeking orienting support from the videos in the ICTMOOC: they were interested to find out which tasks they were to solve, how to engage in solving the tasks and the potential of the available software they were to use. By providing such
} 
support, the videos set up the learning process, introduced the tasks to the learners and revealed the potential of the available software.

\subsubsection{Executive support}

The students relied on the videos while engaged in the assigned tasks (Figure 3):

I heavily relied on the videos: I paused them and did the same on my computer, had to replay the videos if something was unclear.

I used the videos as an instruction manual to complete the tasks.

I used two computers: I was watching the videos on one computer and was working on the tasks on another computer.

Figure 3. Participants' responses about the executive support of the video resources

The participants reported that the videos were used extensively to provide executive support to complete the assigned task: the students watched the videos simultaneously while working on the task by using either two screens/computers or by pausing the videos and replaying the parts of the videos while performing similar steps to complete the task. In particular, the students emphasised that they appreciated the individual tempo they could learn in (Figure 4):

I think that video teaching is much better than classroom teaching because one can choose an individual tempo to learn at and can easily replay the most difficult parts of the target material.

I found out how useful it was to watch the videos several times particularly at an individual tempo.

I watched pedagogical videos at a higher speed, and I reduced the speed of the tutorials and watched them several times.

Figure 4. Participants' responses about watching videos at an individual tempo

The participants appreciated that their learning tempo could be adjusted to their individual needs: they were able to either increase the speed of the videos, pause the videos or replay the videos several times. In sum, the videos were used by the participants for close executive 
support to complete the assigned tasks while adjusting to the participants' individual learning needs.

\subsubsection{Controlling support}

The participants reported that the videos were also used to compare the learning outcomes of the assigned tasks with the criteria outlined in the videos (Figure 5):

I tried to complete the tasks myself first and then I watched the videos to make sure I had done the right thing.

I was able to complete several tasks on my own, however, I watched the videos to make sure

I did not miss any information presented explicitly in the videos.

I watched the videos to assess and evaluate my outcomes against the criteria outlined in the videos.

Figure 5. Participants' responses about the controlling support of the video resources

Several participants indicated that they watched the videos for revision and reflection purposes (Figure 6):

I paused the videos to be able to reflect.

I used the videos to revise what I had learnt in the Module.

Figure 6. Participants' responses about the use of videos for revision and reflection

The videos assisted the learners to compare the criteria of the learning outcomes outlined in the videos with the outcome they achieved. In doing so, the videos helped the learners to clarify the required criteria, validate the outcomes of the completed tasks and structure learners' knowledge when revising and reflecting on the target material.

\subsubsection{Other support}

Although some responses of the participants provided valuable information about the use of videos in the ICTMOOC, these responses were given by individual participants and they do not reflect the patterns of responses provided by the students. However, by following a detailed approached to thematic analysis (Philipsen et al., 2019), these responses were also analysed by the research team and grouped under the theme 'Other support'. For example, a few participants 
indicated that the videos in the ICTMOOC were used as a starting point to find other similar video resources available on the Internet (Figure 7):

I used the videos to find resources from Khan Academy that are specifically designed to support teaching mathematics.

Figure 7. Participants' responses about the use of videos to find similar resources on the Internet

Other participants explicated their positive attitude towards videos as learning resources (Figure 8):

I have become motivated to learn from videos rather than from reading texts. Thank you for good pedagogical videos and tutorials. They are very useful.

Figure 8. Participants' responses about their positive attitude to the use of videos in the ICTMOOC

In addition, some participants put effort to compare the content of the videos with the textual information on the webpages (Figure 9):

I watched the videos and compared the content of the videos with the information on the webpage, in some cases, I noticed some differences.

Figure 9. Participants' responses about the use of videos to compare the information on the webpage and the content of the videos

Other participants indicated the need for updated software (Figure 10):

Videos are central in the ICTMOOC and therefore it is utterly frustrating if the software that is presented in the videos is not updated to its latest version.

Figure 10. Participants' responses about the need for updated software presented in the videos

To summarise, individual learners used the videos as a starting point to find additional resources available on the Internet and compare the information in the videos with the textual information on the webpages in the course. In addition, the videos may have fostered a positive attitude of the participants to learning in the ICTMOOC.

\subsection{Discussion}

The analyses performed in this study focused on examining the types of support videos provided to the pre- and in-service teachers, the preferred length of videos in the ICTMOOC and the implications of participants' interactions with video resources for enhancing their 
agentic capacity to learn and transformative digital agency by addressing the following research questions: What did the pre-and in-service teachers say about the support the video resources in the ICTMOOC provided and what length of videos was preferred by the learners? And what are the implications of the support provided by the videos for enhancing participants' agentic capacity to learn and transformative digital agency?

The patterns of support the videos provided to the participants are presented in Table 6.

Table 6. Patterns of video support in the ICTMOOC

\begin{tabular}{|c|c|}
\hline Type of support & \begin{tabular}{|l} 
Description of support \\
\end{tabular} \\
\hline Orienting support & $\begin{array}{l}\text { - } \quad \text { Setting up the learning process } \\
\text { - } \quad \text { Creating an overview of the target material and the assigned tasks } \\
\text { - } \quad \text { Introducing the assignments to the participants } \\
\text { - } \quad \text { Outlining the criteria of the learning outcomes } \\
\text { - } \quad \text { Revealing the potential of the functions in the available software }\end{array}$ \\
\hline Executive support & $\begin{array}{l}\text { - Facilitating participants' engagement with the tasks by providing step-by-step } \\
\text { guidance about how to complete the task } \\
\text { - } \quad \text { Adjusting to individual learning needs (tempo and multiple viewings) } \\
\text { - Support to engage in learning new concepts }\end{array}$ \\
\hline Controlling support & $\begin{array}{l}\text { - Clarifying the criteria of the learning outcomes } \\
\text { - Support to compare and evaluate learning outcomes against the criteria outlined } \\
\text { in the videos } \\
\text { - Revision and reflection }\end{array}$ \\
\hline Other support & $\begin{array}{l}\text { - As a starting point to search other video resources available on the Internet } \\
\text { - Videos as useful learning resources in online environments } \\
\text { - The need for updated videos } \\
\text { - The need to establish coherence between the content of the webpage and the } \\
\text { content of the videos. }\end{array}$ \\
\hline
\end{tabular}

First, the analyses of the types of support the videos provided to the learners revealed that the videos in the ICTMOOC: i) created an overview of the target material and the assigned tasks, introduced the assignments, outlined the criteria for learning outcomes and revealed the potential of the available software, ii) assisted learners' engagement with the assigned tasks by providing a step-by-step guidance about how to complete the task and adjusted the speed of the learning process to the individual needs of the pre- and in-service teachers, iii) clarified the criteria for learning outcomes, assisted the participants in assessing their outcomes against the criteria presented in the videos. In addition, the videos were used as a starting point to search other resources available on the Internet and may have contributed to enhancing a positive attitude of the pre- and in-service teachers to learning in the ICTMOOC. These findings partly corroborate with the research about the purposes of videos in online courses (Bonafini et al., 
2017) and extend them by specifying the types of support the videos in the ICTMOOC provided to the pre- and in-service teachers. The quantitative data showed that the videos provided more executive than any other types of support. This might potentially indicate that pre- and inservice teachers require more assistance and guidance when engaged in the assigned tasks aimed at developing learners' digital skills.

Second, Galperin's types of orientation may serve as a cue to reveal how the support provided by the videos in the ICTMOOC might have contributed to enhancing the participants' agentic capacity to learn and their transformative digital agency. From the perspective of Galperin's types of orientation, the learners were engaged in the learning process with the third type of orientation: complete and constructed by learners following an offered approach. By providing orienting, executive and controlling support the videos offered an approach showing how to engage in the learning process, complete the assigned tasks and validate the achieved learning outcomes against the criteria outlined in the videos. In doing so, the videos structured the learning process and might have enhanced the participants' understanding about how to go about learning in the ICTMOOC, propel themselves forward as learners and enhance their agentic capacity to learn (Edwards, 2015; Mäkitalo, 2016; Pintrich, 2002; Pintrich \& Zusho, 2002; Zimmerman, 2002, 2008). However, by interacting closely with the video resources, the learners might have demonstrated their dependency on the videos and the support the videos provided.

Third, by providing orienting, executive and controlling support, the videos might have contributed to enhancing transformative digital agency with the pre- and in-service teachers (Brevik, et al., 2019). Learning in the ICTMOOC and the need to solve the assigned tasks involved challenges to master new software or digital tools. In such a situation, the videos were utilised by the participants as mediating objects that helped the learners to engage with the target software and complete the assigned task. In doing so, the videos in the ICTMOOC might have contributed to transforming learning and teaching practices of the participants and might have enhanced the development of transformative digital agency with the pre- and in-service teachers. The learners expressed their satisfaction with the videos: the majority of participants were very strongly satisfied with the videos and over $80 \%$ of enrolled participants completed the ICTMOOC in 2014-2018.

Finally, while the participants were strongly satisfied with the use of videos, the majority of learners considered the length of videos in the ICTMOOC as appropriate (average length of videos is $06 \mathrm{~min} 03 \mathrm{sec}$ ). Specifically, the participants preferred the videos in the range of 5-6 min and the videos in the range of 7-10 min. 
To summarise, by providing orienting, executive and controlling support, the videos closely assisted the pre- and in-service teachers in their learning in the ICTMOOC and might have contributed to enhancing the pre- and in-service teachers' agentic capacity to learn and their transformative digital agency. In addition, in the ICTMOOC the learners preferred the videos in the range of 5-10 min.

\subsection{Implications for the design of videos in online courses and directions for further research}

There are several pedagogical implications for the design of videos to assist learning in online courses.

First, the participants' interactions with the videos in the ICTMOOC, revealed the types of support the videos provided to the pre- and in-service teachers: orienting, executive, controlling and other types of support.

The second and perhaps more profound implication is that videos may affect participants' learning in online courses. Students' close interaction with the videos in the ICTMOOC and the specific need for orienting, executive and controlling support, may have implications for the design of videos in online courses. This study, therefore, raises questions about the need for the course developers' awareness of the types of support videos provide to facilitate students' learning and their development as learners. The orienting, executive and controlling support provided by the videos in the ICTMOOC may reveal an approach how to engage and move forward in learning in online courses and in doing so, may contribute to enhancing learners' agentic capacity to learn. By utilising orienting, executive and controlling support provided by the videos, learners master the essence of learning in online environments and a learning activity carries a new function: not as a studied object, but as a tool for studying the essence of the learning. By interacting with videos, participants develop their understanding of the nature of learning in digital environments and their agency as learners might be enhanced. The fact that the videos in the ICTMOOC were mainly used for executive support to complete the assigned tasks indicates the usefulness of tutorials and pedagogic videos to enhance teachers' transformative digital agency needed in the $21^{\text {st }}$-century classrooms within which digital technology is a reality. Also, the preferred length of videos in the range of 5-10 min might have implications for the design of videos in online courses.

The third implication is that Galperin's pedagogical theory appeared to be useful as a lens to analyse the types of support the videos provided and reflect on the significance of this support 
for learning and the development of students as learners. We suggest that this approach may offer new pathways to use Galperin's conceptual contribution in further research to examine educational practices in online environments. Further research will, therefore, benefit from a longitudinal study examining students' learning with the third type of orientation to get an insight into the development of students' understanding of the nature of learning in digital environments and their capacity to be in control of their learning. The limitation of this study is that the analyses are based on the pre- and in-service teachers' reflections about the support the videos provided in the learning process. Further research is therefore needed to examine the actual learning process of the participants in online environments.

These findings, therefore, inform practitioners, MOOCs, online course developers and educational video producers about the types of support videos may provide to learners in MOOCs and online environments. They also emphasise the crucial importance of practitioners' awareness about the types of support videos provide to enhance pedagogy, students' learning and the development of students as learners.

\section{References}

Arievitch I and Stetsenko A (2000) The quality of cultural tools and cognitive development:Gal'perin's perspective and its implications 1. Human Development 43(2): 69-92.

Arievitch IM and Stetsenko A (2014) The magic of signs: Developmental trajectory of cultural mediation.In: Yasnitsky A, van der Veer R and Ferrari M (eds) The Cambridge Handbook of Culturalhistorical Theory. New York: Cambridge University Press, 217-244.

Azevedo R and Cromley J (2004) Does training on self-regulated learning facilitate students' learningwith hypermedia? Journal of Educational Psychology 96(3): 523-535.

Bandura, A. (2001). Social cognitive theory: An agentic perspective. Annual review of psychology 52(1):1-26.

Bandura, A., Barbaranelli, C., Caprara, G., \& Pastorelli, C. (1996). Multifaceted Impact of Self-Efficacy Beliefs on Academic Functioning. Child Development 67(3): 1206-1222. Available at:http://www.jstor.org/stable/1131888

Barnark-Brak L, Lan W and Paton V (2010) Profiles in self-regulated learning in the online learningenvironment. The International Review of Research in Open and Distance Learning 11(1): 62-80.

Bartolome-Pina AR and Steffens K (2015) Son los MOOC una alternativa de aprendizaje? $1 / 4$ AreMOOCs promising learning environments? Comunicar 22(44): 91-99.

Bayne S and Ross J (2014) The pedagogy of the Massive Open Online Course: The UK view. TheHigher Education Academy. Available at: https://www.heacademy.ac.uk/ resources/detail/elt/the_pedagogy_of_the_MOOC_UK_view

Bonafini F, Chae C, Park E, et al. (2017) How much does student engagement with videos and forums in a MOOC affect their achievement? Online Learning Journal 21(4): 223-240.

Bonk CJ (2011) YouTube anchors and enders: The use of shared online video content as a macrocontextfor learning. Asia-Pacific Collaborative Education Journal 7(1): 13-24.

Brevik LM, Gudmundsdottir GB, Lund A, et al. (2019) Transformative agency in teacher education:Fostering professional digital competence. Teaching and Teacher Education 86: 102875.

Calandra B, Brantley-Dias L and Dias M (2006) Using digital video for professional development inurban schools: A preservice teacher's experience with reflection. Journal of Computing in TeacherEducation 22(4): $137-145$.

Castleberry A and Nolen A (2018) Thematic analysis of qualitative research data: Is it as easy as it sounds? Currents in Pharmacy Teaching and Learning 10(6): 807-815.

Choi, H. J., \& Johnson, S. D. (2005). The effect of context-based video instruction on learning andmotivation in online courses. The American Journal of Distance Education 19(4): 215-227. 
Clara` M (2017) How instruction influences conceptual development: Vygotsky's theory revisited.Educational Psychologist 52(1): 50-62.

Clara` M and Barbera` E (2013) Learning online: massive open online courses (MOOCs), connectivism,and cultural psychology. Distance Education 34(1): 129-136.

Clarke V and Braun V (2014) Thematic analysis. In: Teo T (ed.) Encyclopedia of Quality of Life andWell-being Research. New York: Springer, 6626-6628.

Colasante M (2011) Using video annotation to reflect on and evaluate physical education pre-serviceteaching practice. Australasian Journal of Educational Technology 27(1): 66-88.

Conole G (2015) Designing effective MOOCs. Educational Media International 52(4): 239-252.

Creswell JW (2012) Qualitative Inquiry and Research Design: Choosing among Five Approaches.Thousand Oaks: SAGE.

Edwards A (2015) Designing tasks which engage learners with knowledge. In: Thompson I (ed.)Designing Tasks in Secondary Education: Enhancing Subject Understanding and Student Engagement. New York: Routledge, 13-27.

Engeness I (2018) What teachers do: Facilitating the writing process with feedback from EssayCriticand collaborating peers. Technology, Pedagogy and Education 27(3): 297-311.

Engeness I (2019) Teacher facilitating of group learning in science with digital technology and insightsinto students' agency in learning to learn. Research in Science \& Technological Education. Epubahead of print 12 February 2019. DOI: 10.1080/02635143.2019.1576604

Engeness I and Lund A (2018) Learning for the future: Insights arising from the contributions of Piotr Galperin to the cultural-historical theory. Learning, Culture, and Social Interaction. Epub ahead ofprint 6 December 2018. DOI: 10.1016/j.lcsi.2018.11.004.

Evans BJ, Baker RB and Dee TS (2016) Persistence patterns in massive open online courses (MOOCs).The Journal of Higher Education 87(2): 206-242.

Galperin PY (2002) Lectures in Psychology. Moscow: Knizhnyy Dom Universitet.

Goulah J (2007) Village voices, global visions: Digital video as a transformative foreign languagelearning tool. Foreign Language Annals 40(1): 62-78.

Greenberg AD and Zanetis J (2012) The impact of broadcast and streaming video in education. Cisco:Wainhouse Research. Available at: http://www.cisco.com/web/strategy/docs/education/ciscovideowp.pdf (accessed 2 October 2014).

Guo PJ, Kim J and Rubin R (2014) How video production affects student engagement: An empirical study of MOOC videos. In: Proceedings of the first ACM conference on Learning@ scale conference:L@S ’14, pp. 41-50. New York, NY: ACM.

Hew KF (2016) Promoting engagement in online courses: What strategies can we learn from three highly rated MOOCs. British Journal of Educational Technology 47(2): 320-341.

Kennedy J (2014) Characteristics of massive open online courses (MOOCs): A research review,2009-2012. Journal of Interactive Online Learning 13(1): 1-16.

Kim J, Guo PJ, Seaton DT, et al. (2014) Understanding in-video dropouts and interaction peaks inonline lecture videos. In: Proceedings of the first ACM conference on Learning @ scale conference-L@S '14, pp. 31-40. New York, NY: ACM.

Lagerstrom L, Johanes P and Ponsukcharoen MU (2015) The myth of the six-minute rule: Studentengagement with online videos. In: Proceedings of the American Society for Engineering Education,Seattle, WA, 14-17 June 2015. American Society for Engineering Education. Available at: https://www.asee.org/public/conferences/56/papers/13527/download

Langset ID, Jacobsen DY and Haugsbakken H (2018) Digital professional development: Towards acollaborative learning approach for taking higher education into the digitalized age. Nordic Journalof Digital Literacy 13(01): 24-39.

Lee Y-C, Lin W-C, Cherng F-Y, et al. (2015) Using time-anchored peer comments to enhance socialinteraction in online educational videos. In: Proceedings of the 33rd Annual ACM Conference onHuman Factors in Computing Systems, pp. 689-698. ACM.

Lillejord S, Børte K, Nesje K, et al. (2018) Learning and Teaching with Technology in HigherEducation-A Systematic Review. Oslo: Knowledge Center for Education.

Lund, A., Furberg, A., \& Gudmundsdottir, G. B. (2019). Expanding and embedding digital literacies:Transformative agency in education. Media and Communication 7(2): 47-58.

Måkitalo $\AA$ (2016) On the notion of agency in studies of interaction and learning. Learning, Cultureand Social Interaction 10: 64-67.

Miles M and Huberman AM (1994) Qualitative Data Analysis: An Expanded Sourcebook. 2nd ed.Thousand Oaks: Sage Publications Ltd.

Milligan C and Littlejohn A (2014) Supporting professional learning in a massive open online course.The International Review of Research in Open and Distance Learning 15(5): 197-213. 
Patton, M. Q. (2015) Qualitative research and methods: Integrating theory and practice. London: Sage Publications Ltd.

Pea R and Lindgren R (2008) Video collaboratories for research and education: An analysis of collaboration design patterns. IEEE Transactions on Learning Technologies 1(4): 235-247.18 Policy Futures in Education $0(0)$

Philipsen B, Tondeur J, Pynoo B, et al. (2019) Examining lived experiences in a professional development program for online teaching: A hermeneutic phenomenological approach. AustralasianJournal of Educational Technology 35(5): 46-59. https://doi.org/10.14742/ajet.4469.

Pintrich PR (2002) The role of metacognitive knowledge in learning, teaching, and assessing. Theory into Practice 41(4): 219-225.

Pintrich PR and Zusho A (2002) The development of academic self-regulation: The role of cognitiveand motivational factors. In: Wigfield A and Eccles JS (eds) Development of Achievement Motivation. San Diego: Academic, 249-284.

Reutemann J (2016) Differences and Commonalities-A comparative report of video styles and coursedescriptions on edX, Coursera, Futurelearn, and Iversity. In: Khalil M, Ebner M, Kopp M, Lorenz A and Kalz M (eds)Proceedings of the European Stakeholder summit on experiences and best practices in and around MOOCs (EMOOCS 2016), pp. 383-392. Available at: http://emoocs2016.eu/ wpcontent/uploads/2016/02/proceedings-emoocs2016.pdf

Rose KK (2009) Student perceptions of the use of instructor-made videos in online and face-to-face classes. MERLOT Journal of Online Learning Teaching 5(3): 487-495.

Schraw G, Crippen KJ and Hartley K (2006) Promoting self-regulation in science education: Metacognition as part of a broader perspective on learning. Research in Science Education 36(1-2): 111-139.

Serdyukov P and Hill R (2013) Flying with clipped wings: Are students independent in online college classes? Journal of Research in Innovative Teaching 6(1): 54-67.

Sherer P and Shea T (2011) Using online video to support student learning and engagement. College Teaching 59(2): 56-59.

Singh AB and Mørch AI (2018) An analysis of participants' experiences from the first international MOOC offered at the University of Oslo. Nordic Journal of Digital Literacy 13(01): 40-64.

Van Manen M (2016) Phenomenology of Practice: Meaning-giving Methods in Phenomenological Research and Writing. New York: Routledge.

Vygotsky L (1980) Mind in Society: The Development of Higher Psychological Processes. Cambridge: Harvard University Press.

Wang CH, Shannon D and Ross M (2013) Students' characteristics, self-regulated learning, technology selfefficacy, and course outcomes in online learning. Distance Education 34(3): 302-323.

Whatley J and Ahmad A (2007) Using video to record summary lectures to aid students' revision. Interdisciplinary Journal of E-Learning Learning Objects 3(1): 185-196.

Winne PH (1997) Experimenting to bootstrap self-regulated learning. Journal of Educational Psychology 89(3): 397.

Winne PH and Perry NE (2000) Measuring self-regulated learning. In: Boekaerts M, Pintrich PR and Zeidner M (eds) Handbook of Self-regulation. San Diego: Academic Press, 531-566.

Yousef AMF, Chatti MA and Schroeder U (2014) The state of video-based learning: A review and future perspectives. International Journal of Advanced Life Sciences 6(3/4): 122-135.

Zhang D, Zhou L, Briggs RO, et al. (2006) Instructional video in e-learning: Assessing the impact of interactive video on learning effectiveness. Information Management 43(1): 15-27.

Zimmerman BJ (2002) Becoming a self-regulated learner: An overview. Theory into Practice 41(2): 64-70.

Zimmerman BJ (2008) Investigating self-regulation and motivation: Historical background, methodological developments, and future prospects. American Educational Research Journal 45(1): 166-183.

Zimmerman BJ and Bandura A (1994) Impact of self-regulatory influences on writing course attainment. American Educational Research Journal 31(4): 845-862.

Zimmerman BJ and Pons MM (1986) Development of a structured interview for assessing student use of selfregulated learning strategies. American Educational Research Journal 23(4): 614-628.

Irina Engeness is Associate Professor in ICT in Education at the Faculty of Education Østfold University College in Norway. She has written and her research interests include learning and teaching with digital technology and in digital environments (MOOCs) and a Vygotskian theory.

Magnus Nohr is a Lecturer in ICT in Education at Østfold University College in Norway He has written on students' use of video resources in online courses. 
Ammar Bahadur Singh is a $\mathrm{PhD}$ candidate at Østfold University College. He has written and his research interests include learning and teaching practices in MOOCs and digital environments.

Anders Mørch is Professor in Technology and Learning at the Faculty of Educational Sciences, University of Oslo. His main research interest is to understand how tools and artefacts can help people learn together especially distance learning (MOOC), computer base scaffolding (learning analytics) and end-user development (programming and maker spaces in schools). 